DOI: $10.12731 / 2306-1561-2013-4-40$

\title{
MINIMIZATION OF PRODUCTION RISKS DURING VEHICLE MAINTENANCE CONSUMERS CONCRETE MIXTURES
}

\section{Bashmakov I.A., Ostroukh A.V.}

\section{Abstract}

This article provides an overview of existing methods of minimizing risks. It is shown that to identify and minimize risks when performing technology transportation mix concrete road is no specific list of methods used. In a similar technology as the transportation of concrete mixes, apply some techniques to identify and minimize risks. Identified and provides a general list of threats arising from the implementation of transportation technology of concrete mixtures. An approach to determining the reliability of the technology transporting concrete mixtures.

Keywords: operational risks, transport, road transport, the concrete mix, concrete, modeling, customer service.

\section{УДК 338}

\section{МИНИМИЗАЦИЯ ПРОИЗВОДСТВЕННЫХ РИСКОВ ПРИ}

\section{АВТОТРАНСПОРТНОМ ОБСЛУЖИВАНИИ ПОТРЕБИТЕЛЕЙ БЕТОННЫХ СМЕСЕЙ}

\section{Башмаков И.А., Остроух А.В.}

\begin{abstract}
Аннотация
В настоящей статье приведен обзор существующих методов минимизации рисков. Показано, что для выявления и минимизации рисков при выполнении технологии транспортировании бетонных смесей автомобильным транспортом нет конкретного перечня используемых методов. $B$ технологиях, аналогичных транспортированию бетонных смесей, применяются отдельные методы выявления и минимизации рисков. Выявлен и приведен общий перечень угроз, возникающих при выполнении технологии транспортирования бетонных смесей. Предложен подход к определению надежности технологии транспортирования бетонных смесей.
\end{abstract}

Ключевые слова: производственные риски, транспортировка, автомобильный транспорт, бетонная смесь, товарный бетон, моделирование, обслуживание потребителей. 


\section{Введение}

Значительный эффект может быть получен в результате представления процессов производства строительных материалов, в том числе и бетонных смесей, как основной составляющей монолитного железобетонного строительства, их транспортировки на объектах и организации работ в комплексе - в виде единой цепи взаимосвязанных подсистем, а также при разработке новых методов и моделей автотранспортного обслуживания, снижающих производственные риски [1 - 16].

В настоящей статье рассматривается неразрывная цепь «угроза - возмущение риск».

Угроза - потенциально-возможная опасность потери ресурсов предприятия в процессе осуществления технологии транспортирования бетонных смесей.

Возмущение - означает изменение состояния реализовавшейся угрозы под воздействием потенциально-возможной опасности потери ресурсов предприятия в процессе осуществления технологии транспортирования бетонных смесей.

Риск - это реализовавшаяся вероятность потери (понесённый ущерб) автотранспортным предприятием определенной доли своих ресурсов, или проявление дополнительных расходов ресурсов в результате осуществления транспортирования бетонных смесей автомобильным транспортом.

\section{Обзор существующих методов минимизации рисков}

На сегодняшний день, для выявления и минимизации рисков при выполнении технологии транспортировании бетонных смесей автомобильным транспортом нет конкретного перечня используемых методов [5 - 16]. Но в технологиях, аналогичных транспортированию бетонных смесей, применяются отдельные методы выявления и минимизации рисков. Их перечень приведен ниже [1, 2].

1. Для минимизации потенциальных последствий конкретных решений, касающихся транспортирования асфальтобетонных смесей (если решения негативны), используется метод математической оценки тенденций, или метод математической экстраполяции. Суть его заключается в математическом описании закономерностей конкретного процесса транспортирования асфальтобетонных смесей, наблюдаемого в прошлом, и распространении (экстраполяции) этой закономерности на будущее. Следует заметить, что прогнозы будут правильными только в тех случаях, когда закономерности прошлого развития процесса транспортирования смесей сохранятся в будущем, а непредвиденное изменение поведения процессов в будущем снижает качество прогноза. На основании прогноза можно пытаться построить комплекс защитных мер, позволяющий минимизировать риски.

Этот метод не пригоден для выявления и предупреждения рисков, и малопригоден для минимизации рисков именно в технологии транспортирования бетонных смесей, т.к. верность прогноза целиком зависит от сохранения закономерностей прошлого развития, а ситуация на объектах монолитного строительства меняется гораздо чаще чем на месте укладки асфальтобетона. К тому же особенности метода не позволяет совершать оперативную минимизацию рисков. 
2. Метод структурных диаграмм предполагает через анализ особенностей структуры предприятия, занимающегося транспортированием асфальтобетонной смеси, выявление в используемой им технологии возможных рисков и их минимизацию с помощью мер противодействия. Так можно выявить и минимизировать в основном внутренние организационные риски, связанные с качеством работы аппарата управления предприятия и с выполнением функций руководителей, отвечающих за транспортирование смесей.

Применение данного метода к технологии транспортирования бетонных смесей для выявления в ней рисков малоэффективно, а также предполагает лишь некоторую степень их минимизации. Это связано с нацеленностью метода на структуру предприятия, его подразделений, отделов и служб, а не на саму технологию, используемую предприятием. Метод может служить лишь в качестве дополнительного.

3. Еще одним методом выявления риска и его частичной минимизации является составление и анализ карт технологических процессов касающихся транспортирования арболитной смеси. Сущность этого метода сводится к графическому изображению отдельных технологических процессов транспортирования смеси с обозначением их взаимосвязей. Процесс, зафиксированный в конкретной карте, может охватывать какой-то один этап технологии (например, только укладу арболитной смеси в блок бетонирования), все этапы технологии сразу (процесс работы подвижного состава транспортирующего арболитную смесь) или отдельную технологическую цепочку (транспортирование смеси от места выгрузки до блока бетонирования с её последующим распределением в нём).

Минимизация рисков здесь осуществляется за счет попыток оптимизации процессов. Преимуществами данного метода являются: выявление некоторых критических областей технологического процесса транспортирования арболитных смесей и вложенная в суть метода направленность на минимизацию этих критических областей, а также отдельных элементов процесса.

Недостатками этого метода являются: отсутствие возможности оперативного выявления или предупреждения возникающих при реализации рассматриваемой технологии рисков, а также большая степень обобщенности описываемых процессов.

4. Для анализа риска в технологии транспортирования асфальтобетонной смеси автомобильным транспортом и возможной его минимизации, можно привлекать специализированные консалтинговые компании.

Касательно этого метода стоит сказать только то, что к помощи консалтинговых компаний следует прибегать в том случае, если у предприятия не хватает своих специалистов в области выявления возможных рисков, их предупреждения и минимизации при выполнении указанной технологии, а также, если предприятие обладает свободными денежными средствами для оплаты недешевых услуг профессионалов. 
Про недостатки этого метода можно сказать следующее: эффективность аутсорсинга подобного рода непредсказуема, ввиду частных особенностей ведения своей деятельности консалтинговыми компаниями.

Подводя итог анализа перечисленных методов можно утверждать, что некоторые из них несут в себе то, что может помочь в выявлении, предупреждении и минимизации существующих рисков при реализации указанной технологии. Но в целом, эти методы не способны быть ощутимо эффективными, т.к. не могут учитывать особенностей рассматриваемой технологии ввиду отсутствия структуризации последней. Помимо сказанного, стоит добавить, что описанные методы требуют переосмысления и поиска того, что может заменить или серьезно дополнить их при использовании в области минимизации рисков на транспортном производстве.

\section{Риски, возникающие при выполнении технологии транспортировки бетонных смесей \\ В связи с тем, что неконтролируемые риски несут большие потери (как} материальные (ресурсы), так и временные), необходимо выявлять, предупреждать и минимизировать их при выполнении хозяйственных процессов транспортным предприятием.

Авторами исследования выявлен и приведен общий перечень угроз, возникающих при выполнении технологии транспортирования бетонных смесей (рисунок 1, стрелками обозначена взаимосвязь угроз). Данный перечень показывает угрозы, которые ведут к возникновению возмущений и рисков. Их наличие свидетельствует о необходимости выявления всех потенциальных угроз и их наибольшей минимизации.

Примерами реализации конкретных угроз ведущих к рискам, выявленных непосредственно в процессе работы самой технологии транспортирования бетонных смесей являются:

1. Несоблюдение сроков доставки бетонной смеси автомобильным транспортом (автобетоносмесителем). В результате бетонная смесь:

- «сваривается» из-за длительного содержания смеси в миксере автобетоносмесителя. Сваривание бетонной смеси ведет к риску снижения ее эксплуатационных характеристик, что в свою очередь, затрудняет ее укладку и понижает качество готового сооружения.

- излишне «обводняется» в результате попыток предупреждения его «сваривания». Когда в бетонную смесь попадает избыточная вода, она не вступает в химическую реакцию с цементом (который являет собой основу бетонной смеси), так как последний впитывает именно столько влаги, сколько нужно для успешной гидратации. В результате излишняя вода остаётся в бетоне в свободном состоянии. Спустя определённое время она начинает испаряться, а затем высыхает, и ведет к риску образования пор и пустот, существенно снижающих прочность бетона и созданных из него конструкций. 


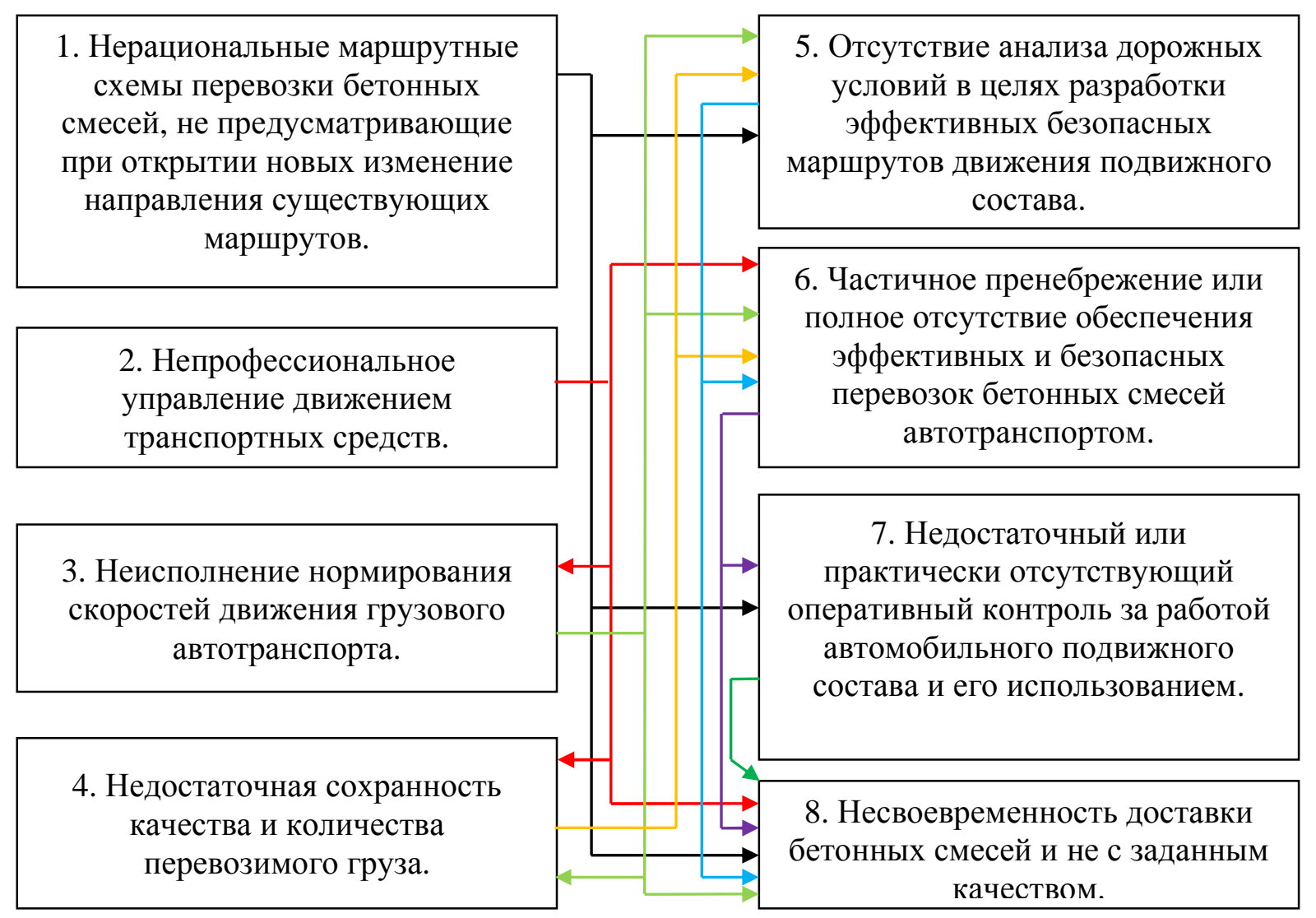

\section{Рисунок 1 - Общий перечень угроз возникающих при выполнении технологии транспортирования бетонных смесей}

2. Несоблюдение сроков выгрузки бетонной смеси автомобильным транспортом (автобетоносмесителем). В результате этого, бетонная смесь может «свариться» или излишне «обводниться». Эти события ведут к риску снижения качества бетонной смеси и, соответственно, качества готового сооружения.

3. Вынужденный перерыв в подаче (задержка выгрузки и задержка доставки) бетонной смеси на место укладки при использовании бетононасоса (не более 40-50 мин.) ведет к риску вынужденного приостановления работы для тщательной промывки бетоновода водой на 20-30 мин.

4. Отсутствие однородности и подвижности бетонной смеси при еe транспортировании. Осадка щебня вниз, и поднятие наверх цементно-песчаного раствора во время транспортирования и разгрузки бетонной смеси, представляет собой её расслоение (потеря однородности). Это ведет к риску неравномерного распределения прочности всей бетонной конструкции.

5. Невозможность подачи автобетоносмесителем смеси в средство ее перемещения в блок бетонирования, или непосредственно в блок бетонирования. В результате возникает риск простоя техники и ухудшения качества бетонной смеси.

6. Невозможность выезда порожнего автобетоносмесителя из ворот или арок на строительном объекте. Автобетоносмеситель разгрузившись увеличивает клиренс на 
несколько сантиметров и не может выехать со строительного объекта. Это ведет к риску простоя транспортного средства из-за операции по стравливанию воздуха из колес и его последующей накачки.

7. Несоответствие технического состояния автомобилей, выпущенных в рейс, Правилам дорожного движения, Правилам технической эксплуатации подвижного состава автомобильного транспорта и инструкциям заводов изготовителей. Приводит к риску возникновения аварийной ситуации в процессе транспортирования бетонной смеси транспортным средством.

8. В рейс выпускаются автомобили, не обеспеченные необходимым исправным противопожарным оборудованием, медицинскими аптечками, знаками аварийной остановки, противооткатными башмаками. Это ведет к риску наложения административного штрафа за несоблюдение Правил дорожного движения и риску возникновения аварии.

Благодаря такому описанию угроз и рисков, сопровождающих технологию транспортировки бетонных смесей, можно судить о существенных потерях, которые несут с собой имеющиеся в ней риски.

\section{Определение надежности технологии транспортирования бетонных смесей}

Надежность системы представляет собой вероятность того, что при функционировании в заданных условиях система будет удовлетворительно выполнять требуемые функции в течение установленного промежутка времени. Показателями надежности процессов при этом являются данные вероятностных значений в интервале 0 $\leq \mathrm{P} \leq 1$. При этом «0» является показателем полного прекращения функционирования, а «1»- показателем полного взаимодействия. Процесс транспортирования бетонной смеси использует для определения качества своей работы такие показатели как: устойчивость, безотказность, восстанавливаемость. Надежность влияет в данном случае именно на восстанавливаемость системы. Поскольку технология транспортирования бетонных смесей может рассматриваться как процесс, то ее надежность допустимо выразить с помощью формулы.

Надежность технологии транспортирования бетонной смеси в течение некоторого времени $\mathrm{t}$ полностью задана функцией $\mathrm{R}(\mathrm{t})$, если известны функции надежности отдельных этапов данной технологии, то есть:

$$
\mathrm{R}(\mathrm{t})=\prod_{\mathrm{i}=1}^{\mathrm{n}} \mathrm{R}_{\mathrm{m}}(\mathrm{t}),
$$

где $\mathrm{R}_{\mathrm{m}}(\mathrm{t})$ - надежность отдельных звеньев технологии транспортирования бетонной смеси. Надежность этих этапов рассчитывается исходя из количества выявленных и учтенных рисков. Для расчета $\mathrm{R}_{\mathrm{m}}(\mathrm{t})$ используются статистические данные. Формула расчета $\mathrm{R}_{\mathrm{m}}(\mathrm{t})$ :

$$
\mathrm{R}_{\mathrm{m}}(\mathrm{t})=\mathrm{e}^{-\lambda \mathrm{t}}
$$


где $\lambda$ - коэффициент риска для определенного этапа технологии транспортирования бетонной смеси; $\mathrm{t}$ - продолжительность определенного этапа технологии транспортирования бетонной смеси (ч); $\mathrm{m}$ - номер этапа.

$$
\lambda=\frac{\mathrm{f}}{\mathrm{h}_{\mathrm{cpi}}}
$$

где $\mathrm{f}$ - суммарное среднее квадратичное отклонение по учитываемым рискам с принятием в расчет их вероятности; $\mathrm{h}_{\text {срі }}$ - средняя вероятность реализации i-го риска.

$$
\mathrm{f}=\sqrt{\frac{\sum_{\mathrm{i}=1}\left(\mathrm{~h}_{\text {опті }}-\mathrm{h}_{\mathrm{cpi}}\right)^{2}}{\mathrm{n}}}
$$

где $\mathrm{h}_{\text {опті }}$ - оптимизированная вероятность реализации $\mathrm{i}-г о$ риска; $\mathrm{h}_{\mathrm{cpi}}-$ средняя вероятность реализации i-го риска; $\mathrm{n}$ - количество учитываемых рисков в звене.

\section{Заключение}

Таким образом, выполнен обзор существующих методов минимизации рисков, применяемых в технологии транспортирования бетонных смесей, а также показаны угрозы и риски, возникающие при выполнении этой технологии.

В результате можно сделать вывод о недостаточной степени рационализации технологии транспортирования бетонных смесей автомобильным транспортом для её использования на современных предприятиях, в условиях неопределенности, многокритериальности и производственных рисков.

\section{Список информационных источников}

[1] Башмаков И.А., Покровский А.К. Математические модели в риск-менеджменте предприятий транспорта. Грузовое и пассажирское автохозяйство. 2010. № 7. С. 30-33.

[2] Башмаков И.А., Покровский А.К. О надежности и рисках в автотранспортных предприятиях. Грузовое и пассажирское автохозяйство. 2011. № 9. С. 66-69.

[3] Башмаков И.А., Покровский А.К., Комаров А.А. Риски производственных процессов. Транспорт: наука, техника, управление. 2012. № 1. С. 65-67.

[4] Будихин С.А. Сравнение методов вращения факторов для управления рисками на промышленных предприятиях / А.В. Остроух, А.В. Будихин, С.А. Будихин // Приборы и системы. Управление, контроль, диагностика. - М.: «Научтехлитиздат», 2008. - №10. - С. 60-63.

[5] Жарков Н.Н. Методы построения корпоративной информационной системы управления ресурсами строительного предприятия / Н.Н. Жарков, Т.В. Дорохина А.В. Остроух, Н.Е. Суркова // Вестник Российского нового университета. Серия естествознание, математика, информатика. - М.: РосНОУ, 2004. - Вып. 4. - С. 110113.

[6] Кузнецов И.А. Особенности реализации автоматизированной информационноаналитической системы центра планирования перевозок строительных грузов / 
И.А. Кузнецов, А.В. Остроух // Вестник МАДИ(ГТУ). - 2008. - Вып. 1(12). - С. $92-$ 96.

[7] Куфтинова Н.Г. Процессно-ориентированный подход к автоматизации планирования и управления транспортировкой продукции предприятий промышленности / А.В. Остроух, Н.Г. Куфтинова // Вестник МАДИ - 2010. - Вып. 4(23). - C. 62-66.

[8] Николаев А.Б. Информационные технологии в менеджменте и транспортной логистике: учебное пособие / А.Б. Николаев, А.В. Остроух. - Saint-Louis, MO, USA: Publishing House Science and Innovation Center, 2013. - 254 c. - ISBN 978-0615-67110-9.

[9] Остроух А.В. Автоматизация распределения транспортных средств и техники по объектам строительства с учетом организационных и технических факторов / A.В. Остроух, Н.Е.Суркова // Приборы и системы. Управление, контроль, диагностика. - М.: «Научтехлитиздат», 2004. - №12. - С. 6-9.

[10] Остроух А.В. Автоматизация и моделирование работы предприятий по строительству промышленных объектов: дис. ... д-ра техн. наук: 05.13.06: защищена 07.04.09: утв. 19.06.09. - М., 2009. - 357 с.

[11] Остроух А.В. Автоматизация и моделирование работы предприятий по строительству промышленных объектов: автореф. дис. ... д-ра техн. наук: 05.13.06. - М., 2009. - 43 c.

[12] Остроух, А.В. Информационные технологии в научной и производственной деятельности / [ред. А.В. Остроух] - М: ООО "Техполиграфцентр", 2011. - 240 с. ISBN 978-5-94385-056-1.

[13] Остроух А.В. Автоматизация управления строительным предприятием / А.В. Остроух // Приборы и системы. Управление, контроль, диагностика. - М.: «Научтехлитиздат», 2004. - №8. - С. 58-61.

[14] Остроух А.В., Башмаков И.А. Процессная модель технологии транспортировки бетонных смесей автомобильным транспортом // Автоматизация и управление в технических системах. - 2013. - № 4.1. - С. 75-81. DOI: 10.12731/2306-1561-20134-14.

[15] Остроух А.В., Джха Прабхакар Автоматизированная система управления складом железобетонных изделий // Автоматизация и управление в технических системах. - 2013. - № 4.1. - C. 51-56. DOI: 10.12731/2306-1561-2013-4-9.

[16] Ostroukh A.V. Workflow automatization in preparation for building / A.V. Ostroukh, D.S. Tarasenko, D.I. Podporin, N.E. Surkova // Information and Telecommunication Technologies in Intelligent Systems: Proceeding of Fourth International Conference. May 27 - June 03, 2006, Catalina, Italy. pp. 102-104. 